\title{
Selective PCAF inhibitor ameliorates cognitive and behavioral deficits by suppressing NF-кB-mediated neuroinflammation induced by $A \beta$ in a model of Alzheimer's disease
}

\author{
SOO-YEON PARK ${ }^{1 *}$, MI-JEONG KIM ${ }^{2 *}$, YOUNG JUN KIM ${ }^{2}$, YOO-HYUN LEE ${ }^{3}$, \\ DONGHYUK BAE ${ }^{4}$, SUNOH KIM $^{4}$, YOUNGHWA NA ${ }^{5}$ and HO-GEUN YOON ${ }^{1}$ \\ ${ }^{1}$ Department of Biochemistry and Molecular Biology, Brain Korea 21 PLUS Project for Medical Sciences, \\ Severance Medical Research Institute, Yonsei University College of Medicine, Seoul; \\ ${ }^{2}$ Department of Food and Biotechnology, Korea University, Sejong; ${ }^{3}$ Department of Food and Nutrition, \\ The University of Suwon, Kyunggi-do; ${ }^{4}$ Jeollanamdo Institute of Natural Resources Research, \\ Jeonnam; ${ }^{5}$ College of Pharmacy, CHA University, Pocheon, Republic of Korea
}

Received September 25, 2014; Accepted February 10, 2015

DOI: $10.3892 /$ ijmm.2015.2099

\begin{abstract}
Several recent studies have reported an association between neurodegeneration and histone modifications, such as acetylation, deacetylation and methylation. In addition, questions have been raised regarding a potential functional role for the histone acetylation enzymes in $\beta$-amyloid (A $\beta$ )-mediated neurotoxicity, particularly the p300/CBP-associated factor (PCAF) enzyme. We recently reported the potential utility of a PCAF inhibitor in the suppression of $A \beta$-induced neuronal cell death, although the in vivo effectiveness of the PCAF inhibitor remained unclear. In this study, we modified the PCAF inhibitor by chemical derivatization and selected compound C-30-27 as the most potent PCAF inhibitor. We demonstrated that C-30-27 selectively inhibited acetylation-dependent nuclear factor- $\kappa \mathrm{B}$

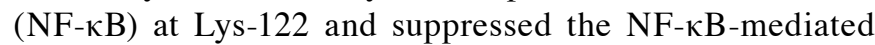
inflammatory response induced by lipopolysaccharide (LPS) or $\mathrm{A} \beta$ in both BV2 and Neuro-2A (N2A) cells. Finally, we demonstrated that C-30-27 improved cognitive deficits, as well as the capacity for locomotion and the damaged cholinergic system in the $A \beta$-treated rats. In conclusion, our results demonstrate
\end{abstract}

Correspondence to: Dr Ho-Geun Yoon, Department of Biochemistry and Molecular Biology, Brain Korea 21 PLUS Project for Medical Sciences, Yonsei University College of Medicine, 134 Shinchon-dong, Seodaemun-gu, Seoul 120-752, Republic of Korea

E-mail: yhgeun@yuhs.ac

Dr Younghwa Na, College of Pharmacy, CHA University, 120 Haeryong-ro, Pocheon-si, Gyeonggi-do 487-010, Republic of Korea E-mail: yna7315@cha.ac.kr

*Contributed equally

Key words: Alzheimer's disease, P300/CBP-associated factor, inflammation, nuclear factor- $\kappa \mathrm{B}$, neurotoxicity, $\beta$-amyloid, cognitive deficit that this selective PCAF inhibitor has the potential to reduce the neuroinflammatory response induced by $A \beta$.

\section{Introduction}

Neuroinflammation is a hallmark of neurodegenerative diseases that is linked to glial cell activation $(1,2)$. This activation is induced by nuclear factor- $\kappa \mathrm{B}(\mathrm{NF}-\kappa \mathrm{B})(3)$, and the abnormal activation of microglia promotes neuronal injury through the release of pro-inflammatory and cytotoxic factors, thus also promoting central nervous system injuries $(4,5)$.

$\mathrm{NF}-\kappa \mathrm{B} / \mathrm{Rel}$ designates a family of transcription factors participating in the activation of a wide range of genes that are crucial players in immune and inflammatory function. Over the years, the NF- $\mathrm{B} / \mathrm{Rel}$ system has been recognized as a central mediator of the rapid and coordinated induction of genes in response to external, primarily pathogenic stimuli (6). NF- $\kappa \mathrm{B}$ has also been shown to control the induction of the transcription of pro-inflammatory mediators, such as cyclooxygenase-2 (COX-2), inducible nitric oxide synthase (iNOS), tumor necrosis factor- $\alpha$ (TNF- $\alpha$ ), interleukin (IL)-1 and IL-6 (7). The transcriptional activity of NF- $\kappa \mathrm{B}$ is activated by acetylation, a task primarily performed by $\mathrm{p} 300 / \mathrm{CBP}$ and p300/CBP-associated factor (PCAF) (8). p300/CBP acetylates multiple lysine residues of $\mathrm{NF}-\kappa \mathrm{B}$, including Lys-122, -123 , $-218,-221$ and -310 (9). However, PCAF specifically acetylates only Lys-122 of NF- $\kappa B(10)$. The blocking of NF- $\kappa B$ acetylation by histone acetyl transferase (HAT) inhibitors diminishes the nuclear retention and transcriptional activity of NF- $\mathrm{B}$ (11-13). Thus, the pharmacological inhibition of HAT activity may be a useful method for the treatment of inflammation.

Previous studies have demonstrated that PCAF knockout mice develop resistance to amyloid toxicity and do not have reduced memory impairment, suggesting the importance of PCAF in the development of neurodegenerative disease (14). In our previous studies, we reported that gallic acid, which inhibits multiple HAT enzymes, including p300 and PCAF, reduced 
$\mathrm{NF}-\kappa \mathrm{B}$ acetylation and activity, and suppressed microglial inflammation $(12,15)$. In addition, we screened PCAF-specific inhibitors using a computer-based molecular docking simulation and found that a PCAF inhibitor that selectively blocked the acetylation of NF- $\mathrm{NB}$ at Lys-122 effectively prevented neuronal cell death caused by $\mathrm{A} \beta$-induced microglial inflammation and neurotoxicity (16). However, the in vivo effectiveness of this PCAF inhibitor remains unclear.

In this study, we further developed this class of PCAF inhibitors by performing chemical derivatization of the parent compound C-30 identified in a previous study (16) and evaluating the activities of the derivatives. We selected C-30-27 as the most potent PCAF inhibitor and evaluated its effects on neuroinflammation, cognitive impairment and damage to the cholinergic system resulting from treatment with $\mathrm{A} \beta$ in vitro or in vivo.

\section{Materials and methods}

Synthesis. The compounds were synthesized using the 4-hydroxybenzaldehyde analogues. Benzaldehyde was $O$-benzylated with proper benzyl chloride under basic conditions. Subsequent condensation with 4-(2-aminoethyl)orpholine or 1-(2-aminoethyl)piperidine yielded imine compounds. Finally, the imine compounds were reduced using sodium borohydride $\left(\mathrm{NaBH}_{4}\right)$ to produce the desired compounds. All the compounds prepared showed consistent spectroscopic data corresponding to the desired structures.

Chemistry (general). The majority of the chemicals and reagents used were obtained from Sigma-Aldrich (St. Louis, MO, USA) and others were from companies, such as Acros Organics (Waltham, MA, USA) and Tokyo Chemicals (Tokyo, Japan). Melting points were measured without correction in open capillaries using the Barnstead Electrothermal melting point apparatus, Manual Mel-Temp (model no. 1202D; Thermo Fisher Scientific Inc., Waltham, MA, USA). Chromatographic separations were monitored by thin-layer chromatography using a commercially available pre-coated Merck Kieselgel $60 \mathrm{~F}_{254}$ plate $(0.25 \mathrm{~mm}$; Sigma-Aldrich) and detected by visualization under UV light at 254 and $365 \mathrm{~nm}$. Silica gel column chromatography was carried out using the Merck Kieselgel 60 plate (0.040-0.063 mm). All solvents used for chromatography were directly used without distillation. NMR spectra were recorded on a Varian AS 400 spectrometer ( ${ }^{1} \mathrm{H}-\mathrm{NMR}$ at $400 \mathrm{MHz}$ and ${ }^{13} \mathrm{C}-\mathrm{NMR}$ at $100 \mathrm{MHz}$ ) (Agilent Technologies, Santa Clara, CA, USA) with tetramethylsilane as an internal standard. Chemical shift $(\delta)$ values are expressed in parts per million (ppm) and coupling constant $(J)$ values in hertz $(\mathrm{Hz})$. Mass spectral investigations were run by liquid chromatography-electrospray ionization-time of flight mass spectrometry (LC-ESI-TOF-MS; Agilent Technologies) in a positive mode.

General synthetic method. A mixture of substituted 4-hydroxybenzaldehyde (1 equivalent), corresponding benzyl chloride (1 equivalent) an potassium carbonate $\left(\mathrm{K}_{2} \mathrm{CO}_{3} ; 1\right.$ equivalent $)$ in dimethylformamide (DMF) was refluxed for 1 day. The reaction mixture was cooled to room temperature and extracted with ethyl acetate. Organic solvent was washed with water, sodium bicarbonate $\left(\mathrm{NaHCO}_{3}\right)$ and brine, and dried over magnesium sulphate $\left(\mathrm{MgSO}_{4}\right)$. The solvent was removed under reduced pres- sure, and the residue was purified by silica gel chromatography to yield $O$-benzylated compounds. The $O$-benzylated compound (1 equivalent) and 4-(2-aminoethyl)morpholine (1 equivalent) or 1-(2-aminoethyl)piperidine in ethanol was refluxed for $2 \mathrm{~h}$ and cooled to room temperature. The solvent was removed under reduced pressure to yield imine compounds. Finally the imine (1 equivalent) and $\mathrm{NaBH}_{4}$ (1.2 equivalent) in ethanol was stirred at room temperature under $\mathrm{N}_{2}$ for $2 \mathrm{~h}$. The reaction mixture was extracted using ethyl acetate. The combined organic solvent was washed with water and dried over $\mathrm{MgSO}_{4}$. The solvent was removed under reduced pressure, and the residue was purified by silica gel chromatography to yiled the final compound, C-30.

In vitro PCAF activity assay. PCAF activity assay was performed using commercially available kits according to the manufacturer's instructions (BioVision, Inc., Milpitas, CA, USA). For in vitro PCAF activity assays, recombinant PCAF proteins (Sigma-Aldrich) were incubated with in vitro acetylation assay buffer [50 mM HEPES pH 8.0, 10\% glycerol, $1 \mathrm{mM}$ DTT, $1 \mathrm{mM}$ phenylmethanesulfonyl fluoride (PMSF), $10 \mathrm{mM}$ sodium butyrate and $1 \mu \mathrm{l}\left[{ }^{3} \mathrm{H}\right]$ acetyl-CoA], $5 \mu \mathrm{g}$ histone $\mathrm{H} 4$ tail peptides and/or the indicated concentration of inhibitors at $30^{\circ} \mathrm{C}$ for $1 \mathrm{~h}$. The samples were separated on a $15 \%$ sodium dodecyl sulfate-polyacrylamide gel electrophoresis (SDS-PAGE) gel and analyzed by autoradiography.

Western blot analysis. Total cell lysate protein was separated with $8 \%$ or $12 \%$ SDS-PAGE and transferred onto nitrocellulose membranes. The membranes were blocked by incubation for $12 \mathrm{~h}$ in $5 \%(\mathrm{w} / \mathrm{v})$ non-fat Difco ${ }^{\mathrm{TM}}$ skim milk blocking buffer. The blocked membranes were incubated overnight at $4^{\circ} \mathrm{C}$ with primary antibodies that recognize iNOS (Cat. no. 160862) (Cayman, AnnArbor, MI, USA), IL-1 $\beta$ (Cat. no. sc-7884) (Santa Cruz Biotech, Dallas, TX, USA), NF- $\kappa$ B (Cat. no. sc-8008) (p65; Santa Cruz Biotech) and $\beta$-actin (Cat. no. A2228) (Sigma-Aldrich). Antibody against Ac(K122)NF- $\mathrm{B}$ was as previously described (16). After extensive washing 3 times with PBS/01\% Tween-20, the membranes were incubated with secondary horseradish peroxidase-conjugated antibody $(1: 1,000)$ for $1 \mathrm{~h}$. The bands were detected with the Enhanced Chemiluminescence System (GE Healthcare, Uppsala, Sweden) according to the manufacturer's instructions.

Cell culture and reagents. BV-2 murine microglial cells and Neuro-2A neuroblastoma cells were obtained from the American Type Culture Collection (ATCC; Manassas, VA, USA). Fetal bovine serum (FBS), trypsin-EDTA and penicillin-streptomycin were purchased from Gibco-BRL ${ }^{\mathrm{TM}}$ (Gaithersburg, MD, USA). 3-(4,5-Dimethylthiazol-2-ly)-2,5-diphenyl tetrazolium bromide (MTT) was purchased from Sigma-Aldrich. A $\beta_{1-42}$ was purchased from Bachem (Bubendorf, Switzerland). Other chemicals were purchased from Sigma-Aldrich. The BV-2 cells were cultured in DMEM (HyClone, Logan, UT, USA) containing 5\% heat-inactivated endotoxin-free FBS, $2 \mathrm{mM}$ glutamine, $100 \mu \mathrm{g} / \mathrm{ml}$ streptomycin and $100 \mathrm{U} / \mathrm{ml}$ penicillin in a humidified $5 \% \mathrm{CO}_{2}$ atmosphere at $37^{\circ} \mathrm{C}$. The Neuro-2A cells were cultured in modified Eagle's medium (MEM; HyClone) containing $10 \%$ heat-inactivated endotoxin-free FBS, $2 \mathrm{mM}$ glutamine, $100 \mu \mathrm{g} / \mathrm{ml}$ streptomycin and $100 \mathrm{U} / \mathrm{ml}$ penicillin in a humidified $5 \% \mathrm{CO}_{2}$ atmosphere at $37^{\circ} \mathrm{C}$. For the co-culture 
experiments, the BV-2 cells were treated with various concentrations of $\mathrm{C}-30-27(0-100 \mu \mathrm{M})$ for $12 \mathrm{~h}$ prior to stimulation with $\mathrm{A} \beta_{1-42}(5 \mu \mathrm{M} ; \mathrm{A} \beta+\mathrm{C}-30-27), \mathrm{A} \beta_{1-42}(5 \mu \mathrm{M})$ alone or medium only (control) for $24 \mathrm{~h}$. Conditioned medium (CM) from the BV-2 cells was collected, centrifuged and transferred to the Neuro-2A cells for a further $24 \mathrm{~h}$. CM from the medium-only treated cells was used as a control. Following incubation, cell viability was measured by MTT assay and reverse transcriptionquantitative PCR (RT-qPCR) was performed.

Cell viability assay (MTT assay). Cell viability was measured using the conventional MTT reduction assay to determine the cytotoxic effects on the BV2 and Neuro-2A cells. Briefly, $5 \times 10^{3}-$ $1 \times 10^{4} \mathrm{BV}-2$ cells were seeded in a 96-well plate. After $12 \mathrm{~h}$ of incubation, the cells were pre-incubated for $24 \mathrm{~h}$ with or without C-30-27, and then incubated with $1 \mathrm{mM}$ of lipopolysaccharide (LPS; Sigma-Aldrich) or $\mathrm{A} \beta_{1-42}(5 \mu \mathrm{M})$ for a further $24 \mathrm{~h}$. The cells were then treated with $15 \mathrm{ml}$ MTT (Sigma-Aldrich) solution $\left(2 \mathrm{mg} / \mathrm{ml}\right.$ ) for $90 \mathrm{~min}$ at $37^{\circ} \mathrm{C}$ and the absorbance was recorded at $570 \mathrm{~nm}$, and a reference was recorded at $630 \mathrm{~nm}$ using a microplate reader (Model 550; Bio-Rad Laboratories, CA, USA).

$R N A$ isolation and RT-qPCR. Total RNA from the BV-2 cells was extracted using TRIzol reagent (Invitrogen Life Technologies, Carlsbad, CA, USA) according to the manufacturer's instructions. The levels of iNOS, COX-2 and IL-1 $\beta$ mRNA were determined by qPCR (ABI PRISM 500 Sequence Detection system; Applied Biosystems, San Jose, CA, USA) cDNA amplification was performed in duplicate in $20-\mathrm{ml}$ reaction mixtures containing $2 \mathrm{X}$ SYBR-Green master mix (Roche, Indianapolis, IN, USA) and $10 \mathrm{pM}$ forward and reverse primers. The initial denaturation step was for $5 \mathrm{~min}$ at $95^{\circ} \mathrm{C}$, followed by 40 amplification cycles: $30 \mathrm{sec}$ at $95^{\circ} \mathrm{C}, 30 \mathrm{sec}$ at $58^{\circ} \mathrm{C}, 30 \mathrm{sec}$ at $72^{\circ} \mathrm{C}$, with a final 10 -min extension at $72^{\circ} \mathrm{C}$.

The results were analyzed using ABI sequence detection software version 2.3. The relative mRNA expression of the target genes was calculated following normalization to GAPDH expression and expressed as the fold induction. The primers used for amplification were as follows: iNOS, 5'-TCTTGG AGCGAGTTGTGGAT and 5'-GGGTGGTAATGTCCAGG AAGT; COX-2, 5'-GAGTGGGAGGCACTTGCATT and 5'-TGGAGGCGAAGTGGGTTTTA; TNF- $\alpha$, 5'-TTCTCATT CCTGCTTGTGGC and 5'-GTTTGCTACGACGTGGGCTA; IL-1 $\beta$, 5'-GTTGACGGACCCCAAAAGAT and 5'-AAGGT CCACGGGAAAGACAC; and GAPDH, 5'-GTGTTCCTACC CCCAATGTGT and 5'-AGGAGACAACCTGGTCCTCAGT.

Animals. Male Sprague-Dawley rats (weight range, 220-240 g) were purchased from the Central Laboratory Animal, Inc. (Seoul, Korea) and housed 7 per cage in a light-controlled room (lights on from 8:00 a.m. to 8:00 p.m.) at a temperature of $22 \pm 2^{\circ} \mathrm{C}$ and a humidity of $50 \pm 5 \%$ with food and water available ad libitum. All experiments were conducted according to the guidelines of the Committee on Care and Use of Laboratory Animals of the Yonsei University College of Medicine, Seoul, Korea.

Experimental groups. The rats were randomly assigned into one of 5 groups as follows: i) the vehicle-injected plus salineadministered group (control group); ii) the $\mathrm{A} \beta_{1-42}$-injected plus saline-administered group ( $\beta$-amyloid group); iii) the
$\mathrm{A} \beta_{1-42}$-injected plus donepezil (Eisai Co., Ltd., Tokyo, Japan)administered group (donepezil group); iv) the $\mathrm{A} \beta_{1-42}$-injected plus low concentration [15 $\mathrm{mg} / \mathrm{kg}$ body weight $(\mathrm{BW}) /$ day] of C-30-27 PCAF inhibitor-administered group (27-L group) and; v) and the $A \beta_{1-42}$-injected plus high concentration (20 mg/ $\mathrm{kg} \mathrm{BW/day)} \mathrm{of} \mathrm{C-30-27} \mathrm{PCAF} \mathrm{inhibitor-administered} \mathrm{group}$ (27-H group). For the induction of $\mathrm{AD}$, the rats were anesthetized with isoflurane [3\%, intra-arterial (i.a); Abbott Animal Health, Wiesbaden, Germany], and placed in a stereotaxic instrument (Harvard Apparatus, Holliston, MA, USA). An incision was made on the scalp of each rat, and the skull was adjusted to position bregma and lambda on the same horizontal plane. Small burr holes were drilled, and $\mathrm{A} \beta_{1-42}(4 \mu \mathrm{g})$ or the vehicle were injected into the hippocampus $(-3.0,2.2$ and $-2.8 \mathrm{~mm})$ using a $5-\mu 1$ Hamilton syringe (Sigma-Aldrich) at a rate of $1 \mu \mathrm{l} / \mathrm{min}$. The hole was then covered with dental acrylic cement and the scalp was closed with sutures. Following surgery, each rat was injected with penicillin in the hindquarter muscle (100,000 units) and individually housed following surgery. All behavioral tests commemced on day 2 following surgery using unanesthetized freely moving rats. Donepezil (1.5 mg/kg BW/day) was administered intragastrically once daily for 7 days before and after the injection of $\mathrm{A} \beta$ into the hippocampus. The C-30-27 PCAF inhibitor was administered during the test period. Artificial cerebrospinal fluid (145 mM NaCl, $2.7 \mathrm{mM} \mathrm{KCl}, 1.2 \mathrm{mM} \mathrm{CaCl}_{2}$, $1.0 \mathrm{mM} \mathrm{MgCl} 2$ ) was used as the vehicle.

Morris water maze test. The water maze test was performed according to standard methods (23) in a circular pool (diameter, $180 \mathrm{~cm}$; height, $75 \mathrm{~cm}$; Iwoo Scientific Co., Seoul, Korea) filled to a depth of $25 \pm 1 \mathrm{~cm}$. The transparent platform $(24 \mathrm{~cm})$ was submerged approximately $1 \mathrm{~cm}$ below the surface of the water, and non-fat milk was added to the water to make it opaque. The first day of the experiment was a swim training day during which the rats swam for $60 \mathrm{sec}$ in the absence of the platform. On each day following the first training day, the rats were subjected to 4 sessions, with an intertrial interval of $5 \mathrm{~min}$. The starting point changed for each session, but the location of the platform was fixed during the entire test period.

The time from being placed into the pool to reaching the platform was measured. On the day after the final training session, each rat was subjected to a probe trial $(90 \mathrm{sec})$ in which no platform was present. The time spent in the target quadrant (the quadrant in which the platform had previously been located) was taken as a measure of spatial memory retention. All data were collected and analyzed using the Smart video tracking system (Smart version 2.5.19; Panlab, Barcelona, Spain).

Passive avoidance test. The rats were tested for memory retention deficits using a passive avoidance apparatus (Iwoo Scientific Co.) as previously described (17). The apparatus consisted of a two-compartment dark/light shuttle box with a guillotine door separating the compartments. The dark compartment had a stainless steel shock grid floor. During the acquisition trial, each rat was placed in the light chamber. After a 60-sec habituation period, the guillotine door was opened, and the latency for the rat to enter the dark chamber (hereafter termed 'initial latency') was recorded. Rats with an initial latency of $>60 \mathrm{sec}$ were excluded from further experiments. Immediately after the rat entered the dark chamber, the 
A<smiles>[R]CCN/C=C/c1cc([R9])c(OC[R])c([R])c1[R]</smiles>

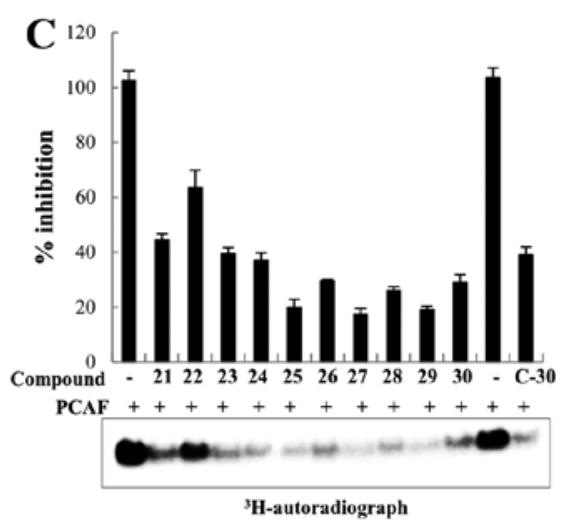<smiles>COc1cc(CNC2CC3CCC(C3)O2)cc(Cl)c1OCc1ccccc1</smiles>

C-30<smiles>COc1cc(CNCCN2CCOCC2)ccc1OCc1cccc(Cl)c1</smiles>

C-30-23<smiles>COc1cccc(COc2c(Cl)cc(CNCCN3CCOCC3)cc2OC)c1</smiles>
C-30-27 C-30-21<smiles>COc1cccc(COc2ccc(/C=N/CCN3CCCCC3)c(OC)c2)c1</smiles>
C-30-22<smiles>COc1cccc(COc2ccc(CNCCN3CCOCC3)cc2OC)c1</smiles>

C-30-25<smiles>COc1cc(OCc2cccc(Cl)c2)ccc1CNCCN1CCOCC1</smiles><smiles>COc1cccc(COc2ccc(CNCCN3CCOCC3)c(OC)c2)c1</smiles>

\begin{tabular}{|l|l|}
\hline Compound & \% Inhibition \\
\hline C-30 & $39.1 \pm 2.82$ \\
\hline C-30-21 & $44.5 \pm 2.12$ \\
\hline C-30-22 & $63.5 \pm 6.36$ \\
\hline C-30-23 & $39.5 \pm 2.13$ \\
\hline C-30-24 & $37.1 \pm 2.88$ \\
\hline C-30-25 & $20.0 \pm 2.83$ \\
\hline C-30-26 & $29.5 \pm 0.71$ \\
\hline C-30-27 & $17.5 \pm 2.09$ \\
\hline C-30-28 & $26.2 \pm 1.41$ \\
\hline C-30-29 & $19.1 \pm 1.42$ \\
\hline C-30-30 & $28.9 \pm 2.87$ \\
\hline
\end{tabular}

Figure 1. Development of a potent p300/CBP-associated factor (PCAF) inhibitor by the chemical derivatization of C-30. (A) General synthetic method of C-30 derivatives. The detailed chemical synthesis is described in Materials and methods. (B) Structure of compound C-30 and its derivatives. (C) Compounds C-30-25, C-30-27 and C-30-29 possessed higher anti-histone acetyl transferase (HAT) activity than the other putative PCAF inhibitors. In vitro HAT activity assays were performed with the indicated HAT enzymes in the presence of chemical compounds $(1 \mu \mathrm{M})$ and a synthetic histone H4 tail peptide.

guillotine door was closed and an electric foot shock (75 V, $0.2 \mathrm{~mA}, 50 \mathrm{~Hz}$ ) was delivered through the floor grid with a stimulator for $3 \mathrm{sec}$. Five seconds later, the rat was removed from the dark chamber and returned to its home cage. Eight hours later, this test was repeated and the latency to enter the dark chamber was recorded (hereafter termed 'retention latency').

Rotarod test. Performance on a rotarod task (five-lane accelerating rotarod; Jeung Do Bio \& Plant, Seoul, Korea) was used to measure motor balance and coordination as previously described (17). The rats were placed on a horizontal rotating rod (diameter, $8 \mathrm{~cm}$; rotation speed, $20 \mathrm{rpm}$ ) and were left on the rod for $5 \mathrm{~min}$ or until they fell off. Falling off the rod activated a switch that automatically stopped a timer. Five rats separated by large disks were tested simultaneously. On the testing day, each rat was submitted to 3 trials with an inter-trial interval of $10 \mathrm{~min}$.

Vertical pole test. The vertical pole test (Iwoo Scientific Co.) was performed as previously described (17). The rats were tested for measuring grip strength and sensorimotor performance on a vertical pole $(2 \mathrm{~cm}$ in diameter, $60 \mathrm{~cm}$ high). The rats were placed on the center of the pole, which was fixed in a vertical position. Rats with deficits in grip strength and sensorimotor performance fell off the pole. Rats were habitu- ated to the task by undergoing 2 trials/day for 2 days. On the testing day ( 3 rd day), 3 measures were taken over 3 trials/rat.

Measurements of acetylcholine (ACh) content and acetylcholinesterase (AChE) activity. The ACh content was determined according to the method of Vincent (18). Aliquots (20 $\mu \mathrm{l})$ of brain homogenate and $50 \mu \mathrm{l}$ of $1 \%$ hydroxylamine were added to a 96-well plate and incubated for $15 \mathrm{~min}$ at $25^{\circ} \mathrm{C}$, followed by the addition of $250 \mu \mathrm{l}$ iron(III) chloride $\left(\mathrm{FeCl}_{3}\right)$ (in $0.1 \mathrm{~N}$ $\mathrm{HCl}, \mathrm{pH} 1.2 \pm 0.2$ ). The absorbance was read at $540 \mathrm{~nm}$ and calibrated with a blank. AChE activity was determined by the colorimetric method described by Ellman (19). A total of $20 \mu$ lof 5,5'-dithio-bis(2-nitrobenzoic acid) (DTNB, $0.01 \mathrm{mM}$; Sigma-Aldrich) and $10 \mu 1$ of brain homogenate in $0.1 \mathrm{mM}$ sodium phosphate buffer ( $\mathrm{pH} \mathrm{8.0)}$ were added to a 96-well plate and incubated for $5 \mathrm{~min}$ at $25^{\circ} \mathrm{C}$. The reaction was then initiated by the addition of $10 \mu \mathrm{l}$ of $0.1 \mathrm{M}$ acetylthiocholine (acetylthiocholine chloride; Sigma-Aldrich). The hydrolysis of acetylthiocholine was monitored by the formation of yellow 2-nitro-5-sulfidobenzene-carboxylate anion resulting from the reaction of DTNB with thiocholine for $10 \mathrm{~min}$ at a wavelength of $412 \mathrm{~nm}$.

Statistical analysis. The results are expressed as the means $\pm \mathrm{SD}$. The data were statistically evaluated using the Student's t-test or one-way analysis of variance (ANOVA) followed by Duncan's 

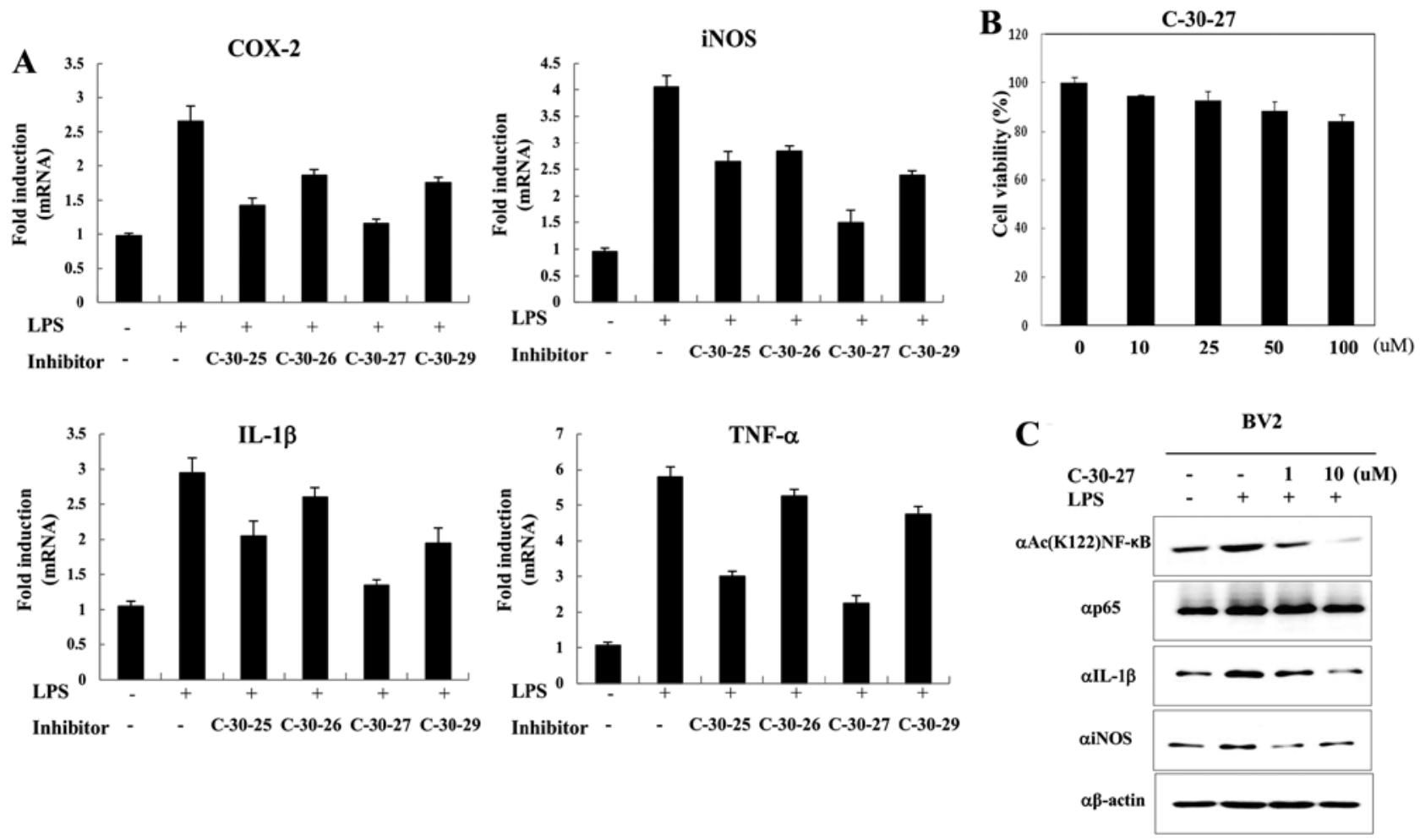

Figure 2. Compound C-30-27 inhibits the lipopolysaccharide (LPS)-induced cytokine production through the inhibition of nuclear factor- $\mathrm{kB}$ (NF-kB) acetylation on Lys-122. (A) C-30-37 exerted the highest inhibitory activity against LPS-induced cytokine production. Total RNA was prepared from each sample and used in RT-qPCR. Columns are the averages of 3 independent experiments; bars indicate the means \pm SD. (B) Cell cytotoxicity to different doses of C-30-27 was measured by MTT assay. (C) C-30-27 suppressed the acetylation of NF- $\mathrm{KB}$ at Lys-122 and cytokine production. The level of p65 acetylation was assayed by western blot

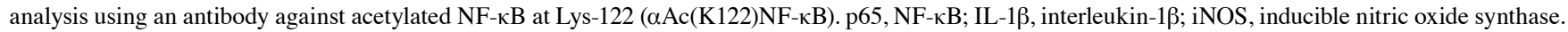

multiple range test to compare significant differences between the groups at $\mathrm{P}<0.05$.

\section{Results}

Inhibitory effect of the PCAF inhibitor, C-30-27, against the acetylation of $N F-\kappa B$ on Lys-122. In our previous study, we screened several PCAF inhibitors using computer-based molecular docking simulation (16). Among those candidates, we selected C-30 for chemical derivatization and synthesized 10 derivatives (Fig. 1A and B). We then assessed the inhibitory activities of these derivatives against the PCAF enzyme by an in vitro acetylation assay. We selected compound 25 (C-30-25), compound 26 (C-30-26), compound 27 (C-30-27) and compound 29 (C-30-29), all of which showed greater inhibition against PCAF activity than the other compounds tested (Fig. 1C). We then determined the inhibitory effects on the expression of cytokines, such as COX-2, iNOS, IL-1 $\beta$ and TNF- $\alpha$ induced by LPS in BV2 cells by RT-qPCR (Fig. 2A). Of the tested compounds, C-30-27 showed the highest inhibitory effects on cytokine expression. Therefore, we selected C-30-27 as our lead PCAF inhibitor candidate.

To examine the effects of our compounds on cell cytotoxicity, we treated the BV-2 cells with 0-100 $\mu \mathrm{M} \mathrm{C}-30-27$ for $24 \mathrm{~h}$ and evaluated cell viability by MTT assay. Treatment with $0-25 \mu \mathrm{M}$ C-30-27 did not have an effect on cell viability; however, treatment with 50-100 $\mu \mathrm{M}$ of C-30-27 induced cell cytotoxicity (Fig. 2B). Based on these results, we selected a C-30-27 concentration of $10 \mu \mathrm{M}$ for further experiments in which we determined whether the inhibition of PCAF blocks the acetylation of NF- $\kappa \mathrm{B}$ and suppresses NF- $\kappa \mathrm{B}$ activity in LPS-treated BV2 cells. As either treatment with LPS or with antibody $(\mathrm{Ab})$ has been shown to commonly induce the PCAF-mediated acetylation of $\mathrm{NF}-\kappa \mathrm{B}$ on Lys-122 (12,16), we then examined whether the PCAF inhibitor, C-30-27, suppresses the LPS-induced NF- $\kappa$ B acetylation at Lys-122. As expected, treatment with LPS robustly induced the acetylation of NF- $\kappa \mathrm{B}$ at Lys-122. However, treatment with C-30-27 substantially reduced the level of NF- $\kappa \mathrm{B}$ acetylation at Lys-122. Moreover, the levels of NF- $\kappa B, I L-1 \beta$ and iNOS were consistently decreased by treatment with C-30-27 (Fig. 2C). Collectively, we selected C-30-27 as a potent PCAF inhibitor for the suppression of the NF- $\mathrm{NB}$-mediated inflammatory response.

The PCAF inhibitor, $C-30-27$, prevents amyloid $\beta$-induced neuronal cell death and suppresses cytokine production. We previously demonstrated that treatment with $\mathrm{A} \beta$ effectively induced the activation of $\mathrm{NF}-\kappa \mathrm{B}$ by increasing the acetylation of NF- $\kappa \mathrm{B}$ at Lys-122, leading to the upregulation of cytokines $(11,16)$. Therefore, we then evaluated the inhibitory effects of C-30-27 against cytotoxicity and cytokine production induced by $A \beta$ (Fig. 3A). First, we examined the effects of C-30-27 on the viability of BV-2 microglial cells and Neuro-2A neuroblastoma cells by MTT assay. Treatment with C-30-27 (0-100 $\mu \mathrm{M})$ did not affect the viability of either cell line (Fig. 3A, left panel). However, the high concentration of C-30-27 $(100 \mu \mathrm{M})$ was slightly toxic to both the BV-2 and Neuro-2A cells, suggesting that an appropriate concentration for further testing is below $50 \mu \mathrm{M}$. We then examined the effects of 
A

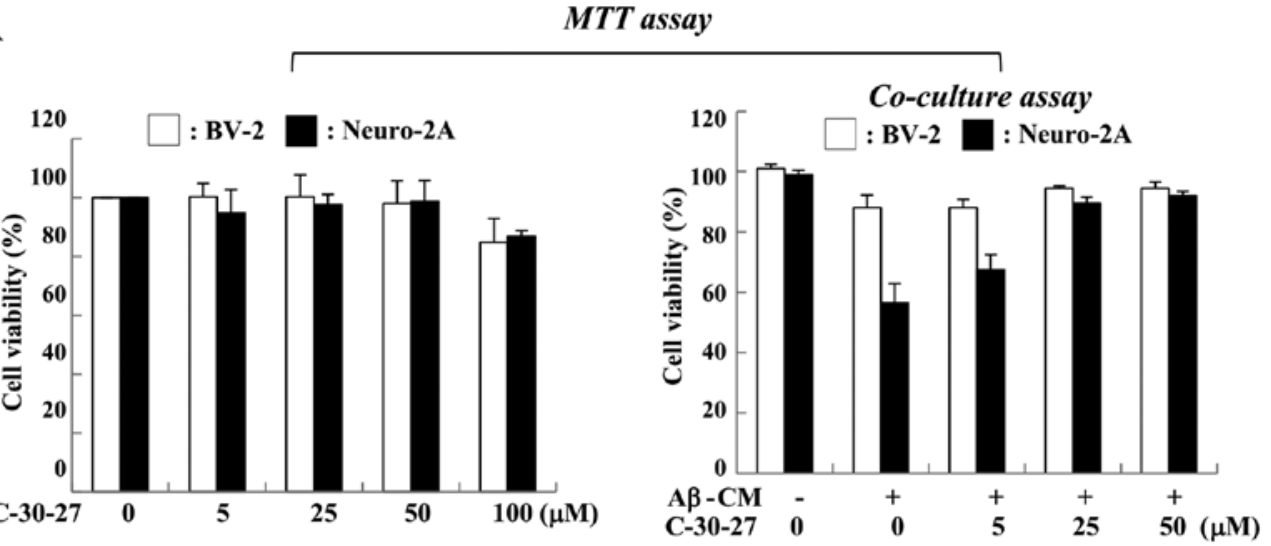

B

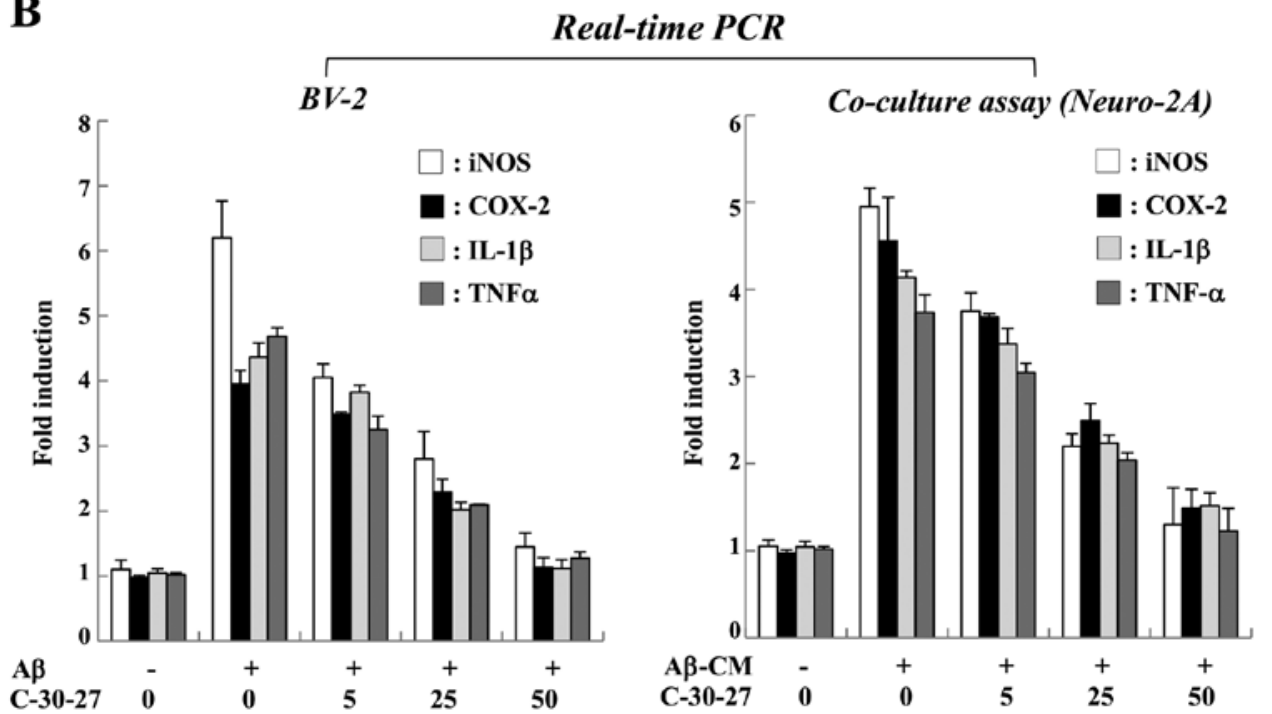

Figure 3. Compound C-30-27 suppresses the microglial-mediated cytokine production and neurotoxicity induced by A $\beta$. (A) Treatment with C-30-27 prevented A $\beta$-induced neuronal cell death. The conditioned medium from BV-2 microglial cells was transferred to the Neuro-2A cells, and cell viability was assessed by MTT assay. (B) Effects of the p300/CBP-associated factor (PCAF) inhibitor, C-30-27, on the expression of cytokines in Neuro-2A cells was analyzed by qPCR. Columns represent the averages of 3 independent experiments and error bars represent the standard deviations.

$\mathrm{A} \beta$-induced microglial activation on neuronal cell survival. For this experiment, $A \beta_{1-42}$-treated conditioned medium (A $\left.\beta-C M\right)$ from the $A \beta$-treated $B V-2$ microglial cells was applied to the Neuro-2A cells, and cell viability was determined by MTT assay. C-30-27 suppressed the A $\beta$-induced Neuro- $2 \mathrm{~A}$ cell death in a dose-dependent manner without affecting the survival of the BV-2 cells, demonstrating the neuroprotective effects of C-30-27 (Fig. 3A, right panel).

As activated microglia-derived cytokines are responsible for neuronal cell death, we then examined whether C-30-27 suppresses cytokine production following $A \beta$-induced microglial activation. Upon treatment with $A \beta$, cytokine production in both the BV-2 cells and A $\beta$-CM-treated Neuro-2A cells was substantially increased (Fig. 3B). As expected, treatment with C-30-27 markedly suppressed the expression of pro-inflammatory cytokines in a dose-dependent manner. These results indicated that $\mathrm{C}-30-27$ prevented $\mathrm{A} \beta$-induced neuronal cell death and cytokine production in the BV-2 and Neuro-2A cells.

Effects of C-30-27 on the A 1-40-induced impairment of memory acquisition and retention. To evaluate the in vivo efficacy of C-30-27 as an inhibitor of neuroinflammation, we carried out several in vivo experiments (Fig. 4A). The effects of C-30-27 on spatial memory were investigated using the Morris water maze test in trials 1-4 on day 4 (Fig. 4B). The escape latencies in the $\mathrm{A} \beta$-treated group were significantly delayed compared to the vehicle-treated control group and showed similar patterns during all 4 days, suggesting that treatment with $A \beta$ effectively induced memory impairment. As expected, donepezil, a palliative medicine for the treatment of $\mathrm{AD}$, improved the spatial memory impairment induced by $\mathrm{A} \beta$. The escape latencies in the C-30-27 low-dose group (27-L) and the C-30-27 high-dose group $(27-\mathrm{H})$ were significantly shorter than the escape latency in the $\mathrm{A} \beta$-treated group in the final trial on day 4 (Fig. $4 \mathrm{C}$ ).

We also performed spatial probe trials to further evaluate the effects of C-30-27, and the results are depicted in Fig. 5A. The time spent in the target quadrant (where the platform was previously placed) was significantly decreased in the $\mathrm{A} \beta$-treated group compared to the control group. However, the time spent in the target quadrant following treatment with C-30-27 was significantly increased. Finally, we evaluated the effects of treatment with C-30-27 on retention latency using the passive avoidance test; the results are depicted in Fig. 5B. In the $A \beta$-treated group, the retention latencies were significantly 

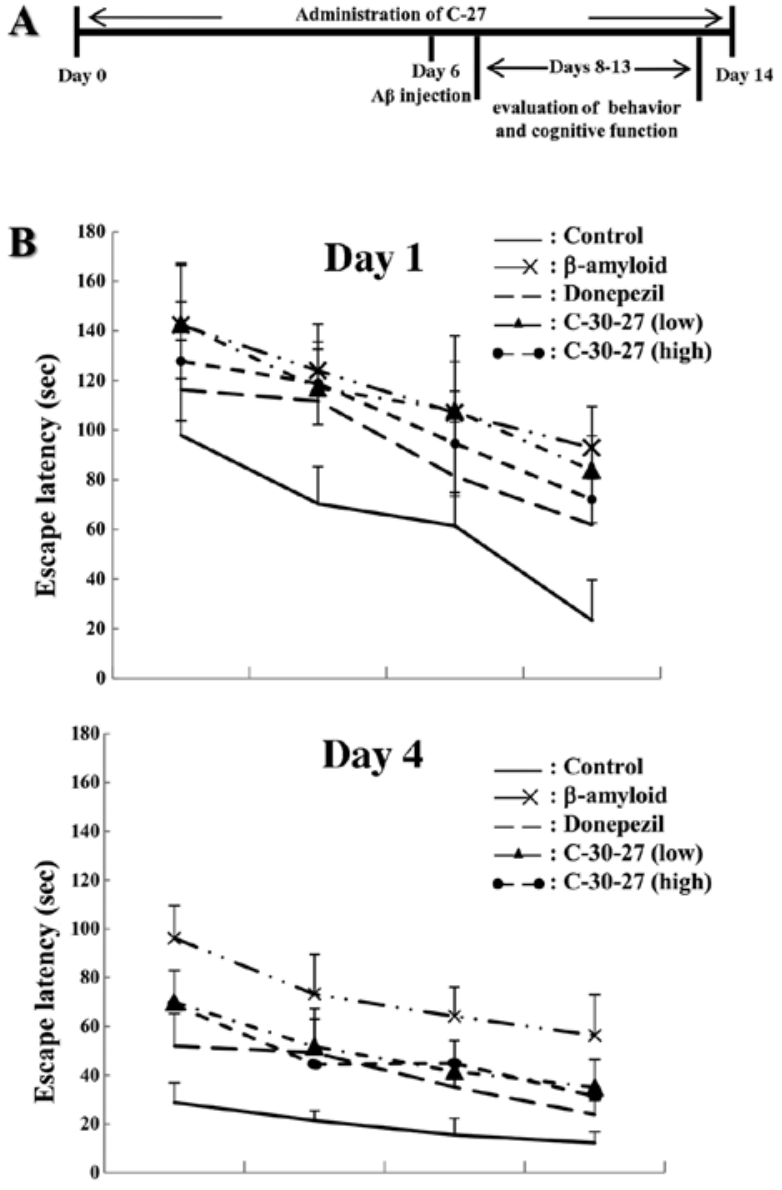

C
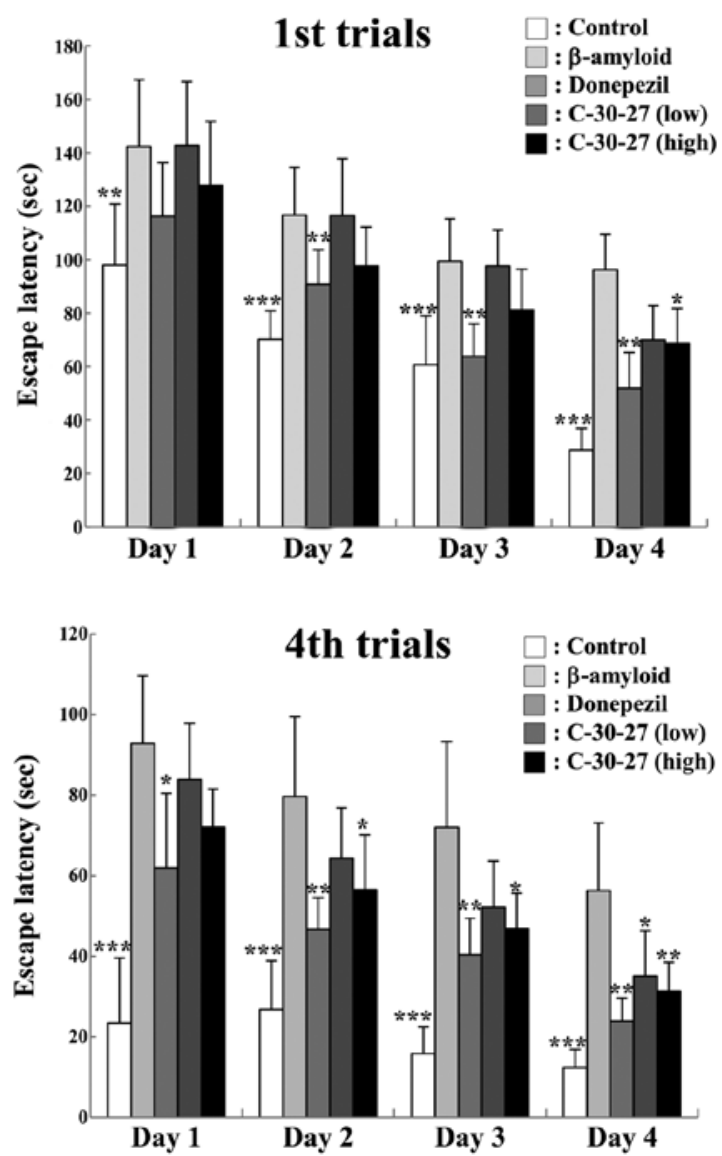

Figure 4. Compound C-30-27 protects against the impairment of memory acquisition and retention by A $\beta$ in the Morris water maze test. (A) Schematic diagram of experiments using mice. Before receiving an intrahippocampal injection of $\mathrm{A} \beta_{1-42}$, the rats were administered C-30-27 for $14 \mathrm{days}$. Donepezil (1.5 mg/kg BW/day) served as a positive control. The rats underwent 4 trials each day for 4 consecutive days. (B) The effects of C-30-27 on the memory of rats impaired by the injection of $\mathrm{A} \beta$ on the 1st and 4th day of the Morris water maze test. (C) The effects of C-30-27 on the memory of rats impaired by the injection of $\mathrm{A} \beta$ in the 1 sth trial and 4th trials of the Morris water maze test over 4 days. Data are expressed as the mean latency \pm SD $(n=8) .{ }^{*} p<0.05,{ }^{* *} p<0.01,{ }^{* * *} \mathrm{p}<0.001 \mathrm{vs}$. the $\beta$-amyloid group. Treated groups were co-treated with A $\beta$ and C-30-27 [15 or $20 \mathrm{mg} / \mathrm{kg}$ body weight (BW)].

decreased in comparison with the control group. However, the decrease in retention latency resulting from $\mathrm{A} \beta$ treatment was alleviated by treatment with donepezil and treatment with the higher dose of C-30-27.

Effects of the PCAF inhibitor, $C-30-27$, on A $\beta$-induced behavioral deficits. The effects of C-30-27 on the behavioral deficits induced by $\mathrm{A} \beta$ were determined using the rotarod and vertical pole tests. In the rotarod test, treatment with $A \beta$ led to a significant decrease in time spent on the rotarod compared to the controls, and treatment with C-30-27 increased the time spent on the rotarod, suggesting that C-30-27 may be effective for the partial recovery of balance and coordination (Fig. 5C). Through the vertical pole test, the times for grip strength and sensorimotor performance were measured. As a result of this test, we found that both the times for grip strength and sensorimotor performance were markedly lower in the animals treated with $\mathrm{A} \beta$; however, treatment with C-30-27 markedly improved the time spent on the vertical pole (Fig. 5D).

Effects of C-30-27 PCAF inhibitor on AChE activity and ACh content in $A \beta$-injected rats. AD is accompanied by synaptic dysfunction in the cholinergic system. Increased AChE activity and a significant loss in the ACh content correlate with cognitive impairments. In addition, it has been shown that the cholinergic system in the brain, which includes ACh receptors, $\mathrm{ACh}$ and $\mathrm{AChE}$, is closely related to the condition of microglial cells in the brain (20). Therefore, we measured $\mathrm{ACh}$ and $\mathrm{AChE}$ activity in the $\mathrm{A} \beta$ - and C-30-27-treated rats.

Following treatment with $\mathrm{A} \beta$, the ACh content was decreased, but $\mathrm{AChE}$ activity was significantly elevated in the $\mathrm{A} \beta$-treated group (Fig. 6). Importantly, treatment with C-30-27 increased the ACh content, leading to the attenuation of AchE activity in the brains of $A \beta$-treated rats. Therefore, these results suggest that the blocking of neuroinflammation by PCAF inhibition ameliorates $\mathrm{A} \beta$-induced cognitive dysfunction, at least in part, which leads to the improvement of function of the cholinergic system.

\section{Discussion}

The present study was conducted to elucidate the biological effects of C-30-27, an inhibitor of acetylation-dependent NF- $\kappa \mathrm{B}$ activation, on microglial-mediated neuroinflammation and the restorative effects on $\mathrm{A} \beta$-induced cognitive dysfunction. $\mathrm{NF}-\kappa \mathrm{B}$ activation is a central event in inflammation and a common feature of a number of neurodegenerative diseases (21). In 

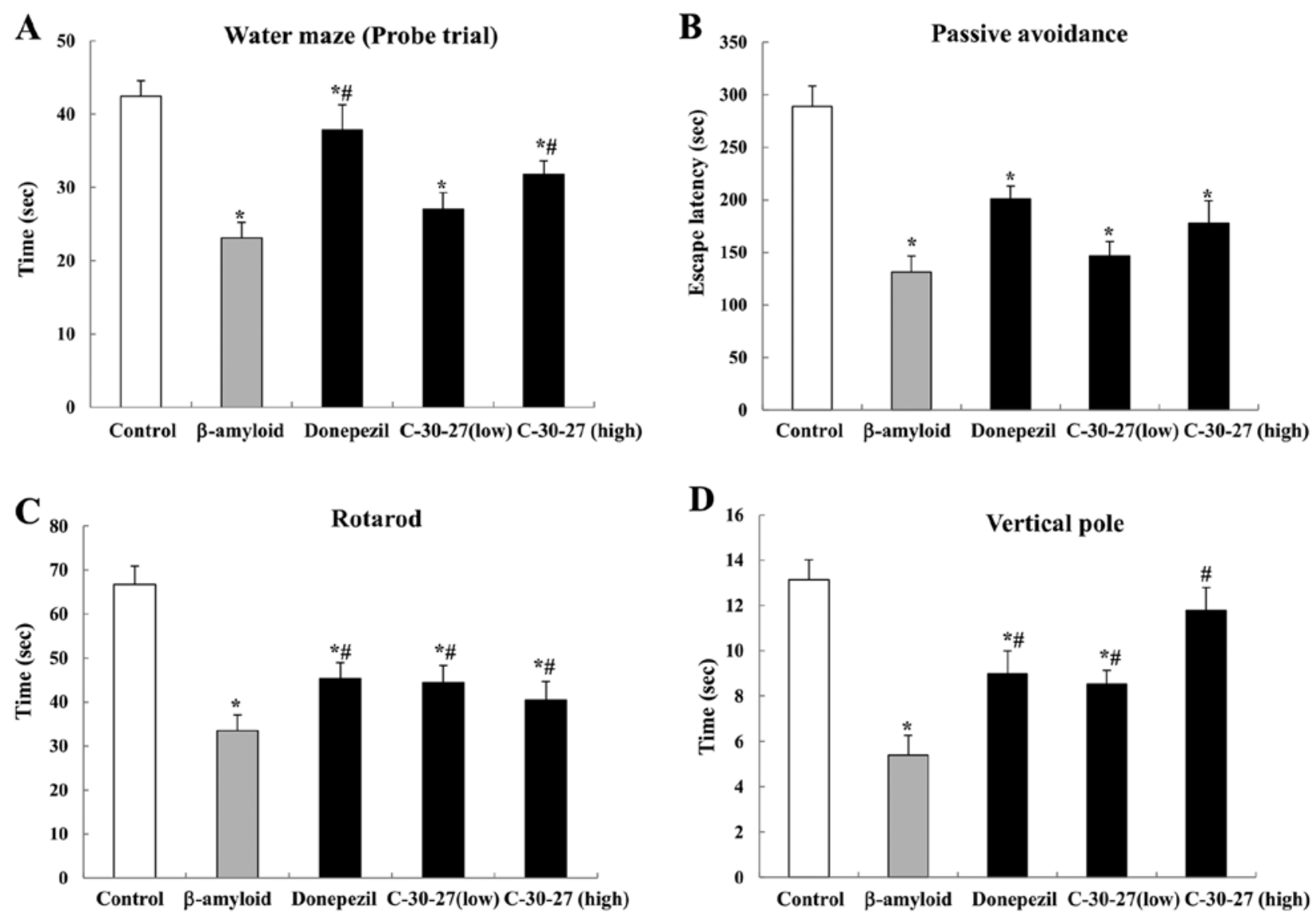

Figure 5. Compound C-30-27 ameliorates A $\beta$-induced cognitive dysfunction in vivo. (A) Effects of C-30-27 on probe trial sessions of the Morris water maze test. The time in the figure represents the cumulative time in the target quadrant of the pool in the $90 \mathrm{sec}$ probe trial. (B) Passive avoidance was measured for 5 min in the shuttle box. Data are expressed as the mean latency $\pm \mathrm{SD}(\mathrm{n}=8) .{ }^{*} \mathrm{P}<0.05$ vs. control; ${ }^{*} \mathrm{P}<0.05$ vs. A $\beta$-injected group. Treated groups were co-treated with $A \beta$ and C-30-27 [15 or $20 \mathrm{mg} / \mathrm{kg}$ body weight (BW)]. (C) Effects of C-30-27 on A -induced motor coordination and balance deficits in the Rotarod test. (D) Effects of $\mathrm{C}-30-27$ on $\mathrm{A} \beta$-induced sensorimotor deficits in the vertical pole test. Data are expressed as the mean latency $\pm \mathrm{SD}(\mathrm{n}=8)$. ${ }^{*} \mathrm{P}<0.05$ vs. control; ${ }^{*} \mathrm{P}<0.05$ vs. $\mathrm{A} \beta$-injected group. Treated groups were co-treated with $\mathrm{A} \beta$ and C-30-27 (15 or $20 \mathrm{mg} / \mathrm{kg} \mathrm{BW}$ ).
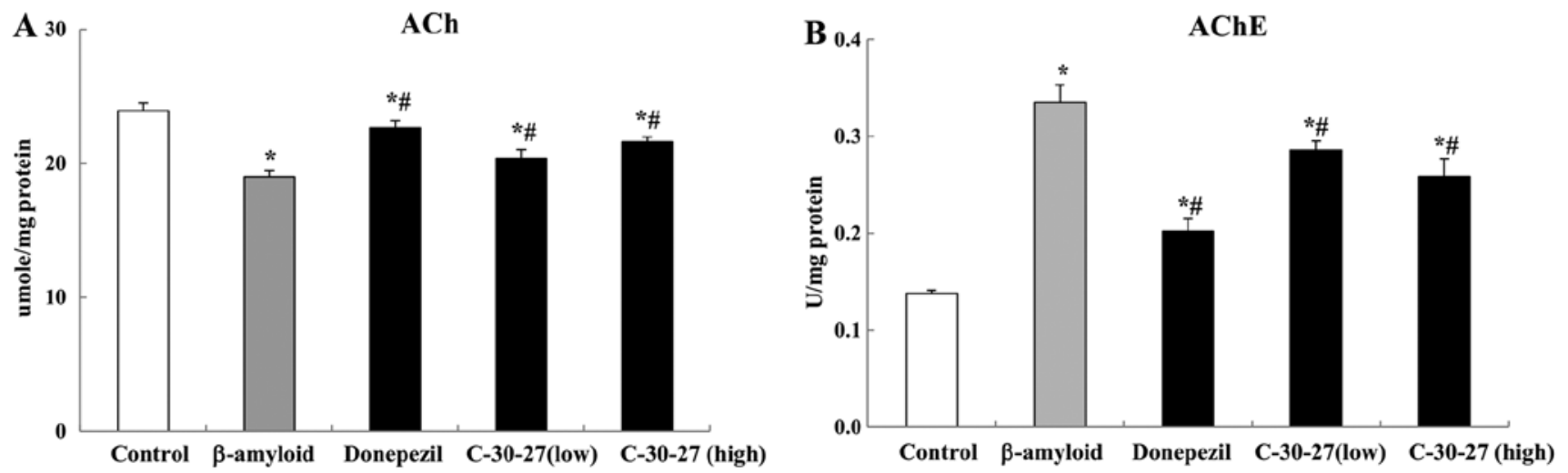

Figure 6. Compound C-30-27 improves the function of the cholinergic system impaired by treatment with A $\beta$. (A) The acetylcholine (ACh) content and (B) acetylcholinesterase (AChE) activity in $A \beta$-injured rats. Data are expressed as the mean latency $\pm \mathrm{SD}(\mathrm{n}=8)$. ${ }^{*} \mathrm{P}<0.05$ vs. control; ${ }^{*} \mathrm{P}<0.05$ vs. $\mathrm{A} \beta$-injected group. Treated groups were co-treated with $A \beta$ and C-30-27 [15 or $20 \mathrm{mg} / \mathrm{kg}$ body weight (BW)].

the brains of patients with $\mathrm{AD}, \mathrm{NF}-\mathrm{\kappa B}$ activation is observed predominantly in neurons and glial cells $(22,23)$. Furthermore, $\mathrm{A} \beta$ has also been shown to activate NF- $\kappa \mathrm{B}$, which leads to increased cytokine production in neurons and glial cells (24). Therefore, the inhibition of NF- $\mathrm{KB}$ activation may be a useful method of blocking $A \beta$-induced neuroinflammation in patients with AD.
As previously demonstrated, HAT enzyme-mediated $\mathrm{NF}-\mathrm{\kappa B}$ acetylation is required for the nuclear translocation and subsequent activation of NF- $\mathrm{BB}$ signaling. Thus, HAT-mediated $\mathrm{NF}-\kappa \mathrm{B}$ acetylation is believed to be a critical step in the NF-kB-mediated inflammatory response, which is presumably correlated with the development of a number of pathological states, particularly those involving acute inflammation, such as 
in $\mathrm{AD}$ (25). In our previous study (16), we confirmed that thespecific acetylation of NF- $\mathrm{NB}$ at Lys-122 by PCAF affected $\mathrm{NF}-\kappa \mathrm{B}$ activity and cytokine signaling. Additionally, we found that the acetylation of NF- $\kappa \mathrm{B}$ at Lys-122 was induced by treatment with $\mathrm{A} \beta$, and the suppression of PCAF had an effect on $\mathrm{NF}-\kappa \mathrm{B}$ activity and neuroinflammation in $\mathrm{A} \beta$-treated neuronal cells and brains (16). Based on these results, in this study, we developed the PCAF inhibitor, C-30, using chemical derivatization and evaluation of the production of cytokines in LPS-treated BV-2 cells. We further evaluated the efficacy of C-30-27 as a specific inhibitor of the acetylation of $\mathrm{NF}-\kappa \mathrm{B}$ using $\mathrm{A} \beta$-treated BV2 cells.

Existing studies, including our previous study, have demonstrated that NF- $\kappa \mathrm{B}$ activation leads to a neuroinflammatory response in the brain and deficient cognitive functions, and the inhibition of $\mathrm{NF}-\kappa \mathrm{B}$ activity improves these biological and functional problems in $A \beta$-treated mice $(12,16,25)$. However, excluding our previous study on gallic acid as an acetylation inhibitor (12), to the best of our knowledge, there are no studies available on the association between a specific chemical acetylation inhibitor of $\mathrm{NF}-\kappa \mathrm{B}$ and cognitive function. Based on these data, in this study, we therefore investigated whether C-30-27, a PCAF inhibitor, ameliorates the effects against $\mathrm{A} \beta$-induced cognitive dysfunction in mice. Previous studies have demonstrated that the $A \beta$-mediated $N F-\kappa B$ activation and cognitive dysfunction is observed in mouse models of $\mathrm{AD}(25,26)$. These studies have supported that $\mathrm{A} \beta$ levels, $\mathrm{NF}-\kappa \mathrm{B}$ activation and cognitive dysfunction are connected. Additionally, using several approaches to inhibit the activation of $N F-\kappa B$ or knockout mice, the evidence gathered thus far suggests roles for $\mathrm{NF}-\kappa \mathrm{B}$ in memory, learning, attention and motivated behavior (27). NF- $\kappa \mathrm{B}$ is involved in the long-term potentiation (LTP) of synaptic transmission in the hippocampus (28), fear memory (29), inhibitory avoidance (30) and consolidation after retrieval (31). As in other studies, we found that weakened memory and learning abilities and the loss of the capacity for locomotion were observed through assessments of the Morris water maze task, passive avoidance test, Rotarod test and vertical pole test. In addition, treatment with C-30-27 restored cognitive deficits and locomotion ability.

In damaged brains such as those in AD, Parkinson's disease (PD) and stroke, it is well known that the cholinergic system is malfunctioning. In particular, exposure to $A \beta$ in $A D$ affects the levels of $\mathrm{AChE}$, butyrylcholinesterase (BuChE), and choline acetyltransferase (ChAT) to favor low levels of ACh (32). In the present study, we also observed significantly enhanced levels of $\mathrm{AChE}$ and decreased levels of ACh in the brains of $\mathrm{A} \beta$-treated rats. However, these levels were significantly recovered following treatment with C-30-27. Thus, the modulation of cholinergic neurotransmission may be a mechanism to improve cognitive deficits.

Of note, we found that the $\mathrm{NF}-\kappa \mathrm{B}$ acetylation inhibitor has the capacity to improve the function of the cholinergic system and cognitive dysfunction. It has been suggested that the dysfunction of the cholinergic system is linked to important neurodegenerative diseases, such as $\mathrm{PD}$ and $\mathrm{AD}$, in which glial activation and local inflammatory processes are known to play important roles (33). These studies maintain that a weakened cholinergic system causes neuroinflammation and ACh can attenuate the production of cytokines from microglia (34). Furthermore, there is evidence from animal studies that directly links acetylcholinesterase inhibitors (AChEIs) with an anti-inflammatory role. For example, galantamine, an AChE inhibitor, has been shown to attenuate the release of cytokines from activated murine microglia (35). In mice, the peripheral administration of AChEIs almost completely blocked cytokine production from activated microglia in the hippocampus and blood (36). Based on our findings, it can be hypothesized that the inhibition of NF- $\kappa \mathrm{B}$ through the suppression of acetylation by a PCAF inhibitor may protect against the induction of abnormal AChE activation and may increase ACh levels during neuroinflammation induced by $\mathrm{A} \beta$.

In conclusion, the results from this study suggest that the selective inhibition of NF- $\mathrm{NB}$ acetylation by the PCAF inhibitor, C-30-27, relieves the inflammatory response in LPS- and A $\beta$-treated BV2-cells and prevents cognitive deficits associated with $\mathrm{A} \beta$ treatment. Therefore, this approach has potential for use as a therapeutic strategy in patients with $\mathrm{AD}$.

\section{Acknowledgements}

This study was supported by a grant from the Korea Health Care Technology R\&D Project, Ministry for Health, Welfare and Family Affairs, Republic of Korea (no. A092039).

\section{References}

1. Holmes C: Review: systemic inflammation and Alzheimer's disease. Neuropathol Appl Neurobiol 39: 51-68, 2013.

2. Sundelof J, Kilander L, Helmersson J, et al: Systemic inflammation and the risk of Alzheimer's disease and dementia: a prospective population-based study. J Alzheimers Dis 18: 79-87, 2009.

3. Kaltschmidt C, Kaltschmidt B, Lannes-Vieira J, et al: Transcription factor NF-kappa B is activated in microglia during experimental autoimmune encephalomyelitis. J Neuroimmunol 55: 99-106, 1994.

4. Ekdahl CT, Kokaia Z and Lindvall O: Brain inflammation and adult neurogenesis: the dual role of microglia. Neuroscience 158: 1021-1029, 2009.

5. Kim YS and Joh TH: Microglia, major player in the brain inflammation: their roles in the pathogenesis of Parkinson's disease. Exp Mol Med 38: 333-347, 2006.

6. Grilli $\mathrm{M}$ and Memo M: Nuclear factor-kappaB/Rel proteins: a point of convergence of signalling pathways relevant in neuronal function and dysfunction. Biochem Pharmacol 57: 1-7, 1999.

7. Jobin C, Morteau O, Han DS and Balfour Sartor R: Specific NF-kappaB blockade selectively inhibits tumour necrosis factoralpha-induced COX-2 but not constitutive COX-1 gene expression in HT-29 cells. Immunology 95: 537-543, 1998.

8. Chen LF and Greene WC: Shaping the nuclear action of NF-kappaB. Nat Rev Mol Cell Biol 5: 392-401, 2004.

9. Chen L, Fischle W, Verdin E and Greene WC: Duration of nuclear NF-kappaB action regulated by reversible acetylation. Science 293: 1653-1657, 2001.

10. Greene WC and Chen LF: Regulation of NF-kappaB action by reversible acetylation. Novartis Found Symp 259: 208-225, 2004.

11. Choi KC, Jung MG, Lee YH, et al: Epigallocatechin-3-gallate, a histone acetyltransferase inhibitor, inhibits EBV-induced $\mathrm{B}$ lymphocyte transformation via suppression of RelA acetylation. Cancer Res 69: 583-592, 2009.

12. Kim MJ, Seong AR, Yoo JY, et al: Gallic acid, a histone acetyltransferase inhibitor, suppresses $\beta$-amyloid neurotoxicity by inhibiting microglial-mediated neuroinflammation. Mol Nutr Food Res 55: 1798-1808, 2011.

13. Seong AR, Yoo JY, Choi K, et al: Delphinidin, a specific inhibitor of histone acetyltransferase, suppresses inflammatory signaling via prevention of NF- $\mathrm{KB}$ acetylation in fibroblast-like synoviocyte MH7A cells. Biochem Biophys Res Commun 410: 581-586, 2011.

14. Duclot F, Jacquet C, Gongora C and Maurice T: Alteration of working memory but not in anxiety or stress response in p300/CBP associated factor (PCAF) histone acetylase knockout mice bred on a C57BL/6 background. Neurosci Lett 475: 179-183, 2010. 
15. Choi KC, Lee YH, Jung MG, et al: Gallic acid suppresses lipopolysaccharide-induced nuclear factor-kappaB signaling by preventing RelA acetylation in A549 lung cancer cells. Mol Cancer Res 7: 2011-2021, 2009.

16. Park SY, Lee YH, Seong AR, Lee J, Jun W and Yoon HG: Selective inhibition of PCAF suppresses microglial-mediated $\beta$-amyloid neurotoxicity. Int J Mol Med 32: 469-475, 2013.

17. Bae D, Kim Y,Kim J,et al: Neuroprotective effects of Eriobotrya japonica and Salvia miltiorrhiza Bunge in in vitro and in vivo models. Animal Cells Systems 18: 119-134, 2014.

18. Vincent D, Segonzac G and Vincent MC: Colorimetric determination of acetylcholine by the Hestrin hydroxylamine reaction and its application in pharmacy. Ann Pharm Fr 16: 179-185, 1958 (In French).

19. Ellman GL, Courtney KD, Andres V Jr and Feather-Stone RM: A new and rapid colorimetric determination of acetylcholinesterase activity. Biochem Pharmacol 7: 88-95, 1961.

20. Das UN: Acetylcholinesterase and butyrylcholinesterase as possible markers of low-grade systemic inflammation. Med Sci Monit 13: RA214-RA221, 2007.

21. Kaltschmidt B, Uherek M, Volk B, Baeuerle PA and Kaltschmidt C: Transcription factor NF-kappaB is activated in primary neurons by amyloid beta peptides and in neurons surrounding early plaques from patients with Alzheimer disease. Proc Natl Acad Sci USA 94: 2642-2647, 1997.

22. Boissiere F, Hunot S, Faucheux B, et al: Nuclear translocation of NF-kappaB in cholinergic neurons of patients with Alzheimer's disease. Neuroreport 8: 2849-2852, 1997.

23. Lukiw WJ and Bazan NG: Strong nuclear factor-kappaB-DNA binding parallels cyclooxygenase- 2 gene transcription in aging and in sporadic Alzheimer's disease superior temporal lobe neocortex. J Neurosci Res 53: 583-592, 1998.

24. Akama KT, Albanese C, Pestell RG and Van Eldik LJ: Amyloid beta-peptide stimulates nitric oxide production in astrocytes through an NFkappaB-dependent mechanism. Proc Natl Acad Sci USA 95: 5795-5800, 1998

25. Zhang J, Zhen YF, Pu Bu Ci R, et al: Salidroside attenuates beta amyloid-induced cognitive deficits via modulating oxidative stress and inflammatory mediators in rat hippocampus. Behav Brain Res 244: 70-81, 2013.
26. Memet S: NF-kappaB functions in the nervous system: from development to disease. Biochem Pharmacol 72: 1180-1195, 2006.

27. Meffert MK, Chang JM, Wiltgen BJ, Fanselow MS and Baltimore D: NF-kappa B functions in synaptic signaling and behavior. Nat Neurosci 6: 1072-1078, 2003.

28. Albensi BC and Mattson MP: Evidence for the involvement of TNF and NF-kappaB in hippocampal synaptic plasticity. Synapse 35: 151-159, 2000.

29. Yeh SH, Lin CH, Lee CF and Gean PW: A requirement of nuclear factor-kappaB activation in fear-potentiated startle. J Biol Chem 277: 46720-46729, 2002.

30. Freudenthal R, Boccia MM, Acosta GB, et al: NF-kappaB transcription factor is required for inhibitory avoidance long-term memory in mice. Eur J Neurosci 21: 2845-2852, 2005.

31. Merlo E, Freudenthal R, Maldonado H and Romano A: Activation of the transcription factor NF-kappaB by retrieval is required for long-term memory reconsolidation. Learn Mem 12: 23-29, 2005.

32. Malmsten L, Vijayaraghavan S, Hovatta O, Marutle A and Darreh-Shori T: Fibrillar $\beta$-amyloid 1-42 alters cytokine secretion, cholinergic signalling and neuronal differentiation. J Cell Mol Med 18: 1874-1888, 2014

33. Streit WJ: Microglia and neuroprotection: implications for Alzheimer's disease. Brain Res Brain Res Rev 48: 234-239, 2005.

34. Tabet N: Acetylcholinesterase inhibitors for Alzheimer's disease: anti-inflammatories in acetylcholine clothing! Age Ageing 35 336-338, 2006

35. Giunta B, Ehrhart J, Townsend K, et al: Galantamine and nicotine have a synergistic effect on inhibition of microglial activation induced by HIV-1 gp120. Brain Res Bull 64: 165-170, 2004.

36. Nizri $\mathrm{E}$, Irony-Tur-Sinai $\mathrm{M}$, Faranesh $\mathrm{N}$, et al: Suppression of neuroinflammation and immunomodulation by the acetylcholinesterase inhibitor rivastigmine. J Neuroimmunol 203: 12-22, 2008. 